RAPHISA.

Revista de Antropología y Filosofía de lo Sagrado Review of Anthropology and Philosophy of the Sacrum

ISSN: 2530-1233 $\mathrm{N}^{\circ}$ 3, diciembre (2018) pp.: 31-65

\title{
SUJETO Y CONSTRUCCIÓN DE LA IDENTIDAD EN LOS SISTEMAS ADIVINATORIOS DE LA SANTERÍA CUBANA
}

\section{SUBJECT AND THE IDENTITY BUILDING IN THE DIVI- NATION SYSTEM OF THE CUBAN SANTERIA}

\author{
Roberto Garcés Marrero1 \\ Universidad Iberoamericana (Ciudad de México)
}

\begin{abstract}
Resumen: El presente trabajo versa sobre cómo se construye una cierta identidad y, por tanto, un cierto tipo de sujeto, a partir de los sistemas normativos propios de la adivinación en la santería cubana. Este análisis se realiza a partir de las experiencias en el trabajo de campo del autor durante cinco años en una "casa de santo" en Remedios, Villa Clara y del estudio exhaustivo de las llamadas "letras" de Ifá. La adivinación en esta religión no solo resulta un acto predictivo, sino una manera de conformar un tipo de personalidad, a partir de un conjunto de reglas y recomendaciones individualizadas para cada creyente.
\end{abstract}

Palabras clave: SANTERÍA CUbANA, SUJETO, IDENTIDAD, SISTEMA ADIVINATORIO

\begin{abstract}
The present research is about how a certain identity is constructed and, therefore, a certain type of subject, based on the normative systems of divination in $\mathrm{Cu}$ ban Santeria. This analysis is based on the experiences of the author's field work during five years in a "casa de santo" in Remedios, Villa Clara and the exhaustive study of the so-called "letters" of Ifá. Divination in this religion is not only a predictive act, but a way to conform a certain type of personality, based on a set of rules and individualized recommendations for each believer.
\end{abstract}

Key words: Cuban SANTERIA, SUbJeCt, IDENTITY, Divination SYSTEM

[1] (rgmar18777@hotmail.com) Doctor en Ciencias Filosóficas (Universidad Central "Marta Abreu" de Las Villas, 2014). Licenciado en Estudios Socioculturales (UCLV, 2007). Impartió clases en la Universidad Central "Marta Abreu" de Las Villas (2007- 2014), en el Colegio Universitario de San Gerónimo de la Universidad de La Habana (2015- 2016) y en la Universidad de Ciencias Médicas de La Habana (2015-2016). Fue jefe del Departamento de Trabajo Comunitario del Centro Nacional de Educación Sexual (CENESEX), La Habana (2014- 2016). Ha impartido clases de postgrado, cursos, talleres y conferencias en Cuba, Colombia, República Dominicana y Panamá. Ha publicado artículos en diferentes publicaciones periódicas, revistas científicas y libros en Cuba, México y Uruguay. Autor del libro Cine, ideología y Revolución (Editorial de Ciencias Sociales, La Habana, 2017). Ha sido miembro del consejo editorial o colaborado como árbitro en revistas especializadas (Cuba, Colombia, Estados Unidos). Es miembro de la Latin American Studies Association (LASA) y de la Red de Ciencias Sociales Interdisciplinares (Common Ground Research Network). 


\section{Introducción}

Según Michael Foucault en Occidente existen una serie de saberes que van prefigurando a los sujetos, los disciplinan, los hacen autogobernados y, por ende, gobernables. La construcción de la identidad se forma en este proceso de autonormalización, de entenderse dentro de determinado marco sociocultural, político, jurídico, moral, económico y religioso. Podríamos preguntar: ¿es posible llevar esa idea más allá del contexto europeo, concretamente francés, en el que Foucault se planteó estas cuestiones? En las sociedades latinoamericanas coexisten instituciones de origen netamente occidental con otras venidas de disímiles regiones geográficas y culturales o endémicas, las cuales se oponen, entremezclan, reafirman. En Cuba, por ejemplo, difícilmente podrá ser entendida la conducta de muchos individuos si solo se piensa desde la regulación legal, sin dudas, muy importante, pero no única en la interrelación de fuerzas actuantes en el ámbito sociocultural cubano.

Si se toma como base la noción de Foucault de que la gubernamentalidad es la estructuración del posible campo de la conducta ${ }^{2}$, esto también sería gubernamental y, sin embargo, al margen de lo estatal, lo legal, lo oficial e incluso en posible conflicto con ese ámbito ${ }^{3}$. Futuras agendas políticas que incluyan ítems como raza, relaciones de género y diversidad sexual e incluso participación ciudadana deberían tener en cuenta este "currículo oculto" de la sociedad cubana, donde la necesidad del principio de la multiplicidad de Deleuze y Guattari se manifiesta en todo su esplendor. Un análisis básico de las relaciones cotidianas de poder tiene que abordarse no desde la diagnosis de una supuesta raíz única: las rizomáticas bases de este poder se trasvasan de lo legal a lo ilegal, de lo oficial a lo no oficial, de lo molar a lo molecular. Siguiendo la inspiración de Deleuze y Guattari, no es suficiente para aprehender la conformación de la identidad y del sujeto en Cuba quedarse en la búsqueda de un eje genético único (en este caso podría ser los poderes-saberes occidentales), sino hay que tomar lo

[2] Foucault, Michel. "El sujeto y el poder". Revista Mexicana de Sociología, Vol. 50, No. 3. (1988), p. 15

[3] Resulta significativo en el caso de Cuba, aunque el código penal reconoce la exhumación ilícita de cadáveres como un delito, (Título III Delitos contra la seguridad colectiva, Capítulo I, artículo 188 Exhumaciones ilegales. En Código Penal de la República de Cuba. Disponible en: http://www.parlamentocubano.cu/ index.php/documento/codigo-penal/) es un elemento de total dominio popular que muchos practicantes, sobre todo de Palo Monte, necesitan para sus rituales desenterrar restos, o al menos partes de los cadáveres, para muchos de sus rituales. Cada uno de estos sacerdotes está en una situación incriminable, que sin embargo es ignorada por la ley. Tal pareciera que ley y religión en este caso, pertenecieran a ámbitos distintos. [4] Deleuze, Gilles y Felix Guattari. Mil mesetas. Capitalismo y esquizofrenia. Valencia, Ediciones Pretextos, 2004, p. 13 
rizomático como principio metodológico ${ }^{5}$ para la comprensión de una cierta realidad múltiple, proteica, en tanto red de fuerzas y de fugas, de raíces entrecruzadas y tallos subterráneos, tendiendo hacia una cartografía de relaciones de poder descentradas, solapadas, actuantes, evanescentes.

La interrogante que planteamos entonces es: ¿resulta posible hablar de la construcción de la identidad, e incluso de un determinado tipo de sujeto en el marco de normas no occidentales pero incluidas en sociedades híbridas, mestizadas por su pasado colonial en este caso concreto, a partir del sistema adivinatorio de la santería cubana? Se podría sostener que el post-estructuralismo poco supo de religiones de origen africano y de las determinaciones concretas de las sociedades del Caribe. Sin embargo, ciertas ideas, sin mimesis posible, pueden ayudar a pensar realidades muy diferentes de aquellas en las cuales surgieron. Por supuesto, en la santería, si se construye un sujeto es a partir de presupuestos, modos y finalidades que nada tienen en común con aquellas que fueron familiares al pensamiento foucaultiano ni con la racionalidad occidental.

En el presente trabajo se hace una diferenciación necesaria entre creación del sujeto y creación de la identidad. Se parte de la idea foucaultiana de que sujeto significa estar sujeto a cierto orden de cosas, sociopolítico, económico y cultural, así como constreñido a, sujeto a cierta identidad, entendida como noción (a menudo limitante, pero sin dudas estructurante) de sí mismo ${ }^{6}$. La identidad se concibe entonces como la interiorización de un orden socioeconómico, político y cultural dado, es decir, la manera en la que el individuo va siendo convertido en un sujeto legible dentro de esta ordenación del mundo social y haciéndose legible a sí mismo dentro de la misma La identidad y su arduo proceso de reinvención constante sería el paso previo para la creación del sujeto, como proyecto inacabado y reinventable siempre. Aquí "previo" se refiere a un simple ejercicio heurístico, en la práctica es indistinguible porque causas y efectos se entremezclan, interdefinen y reproducen. También hay que señalar que como ese orden no es tan ordenado ni homogéneo, no existe una identidad monolítica, mucho menos en una sociedad tan híbrida como la cubana, por tanto, esta identidad siempre será también híbrida y fluida.

Aunque Foucault abordó la cuestión de cómo ciertas prácticas religiosas, especialmente la confesión, han coadyuvado en la conformación del sujeto actual, el tema particular de cómo la religión no occidental, como la santería, configura esta noción estructurante del sí mismo, ha sido poco abordada. En este caso específico, la regulación de la conducta no es para

[5] Deleuze, G y F. Guattari. Op. Cit., pp. 9- 29

[6] Foucault, M, Op. Cit., p. 7 
evitar el pecado o para conseguir un mejor puesto en un futuro paraíso. La idea de pecado, a pesar de toda la influencia que haya tenido el cristianismo en la santería (bastante superficial, de hecho), es totalmente extraña a su cosmovisión y por ende ni siquiera se utiliza. Las nociones escatológicas aquí son muy difusas y aunque por momentos se habla de reencarnación, lo que pase después de la muerte no es objeto de disquisiciones. La relación con el santo u orisha, de hecho, es bastante poco ortodoxa ${ }^{7}$. De lo que tratan casi todas las prácticas de la santería es de evitar la muerte en primer lugar y de conseguir la mayor salud y prosperidad, sobre todo material, posibles aquí y ahora, dentro de los límites que ya están prefijados en un destino escogido de antemano por cada individuo, antes de su nacimiento. Ese "camino", como se le denomina, representado en la adivinación por ciertas combinaciones nombradas signos, letras u oddun, implica que la persona tiene determinadas características que serán inalterables: solo se intenta que cada cual las regule para obtener el mayor bienestar posible. Así hay una amplia aceptación religiosa a comportamientos considerados como inmorales por occidente, a pesar de que también los mismos se limitan o tratan de limitarse, pero son esperados.

A lo largo de este escrito se tratará de ahondar en estas cuestiones. Las bases empíricas para dar estas explicaciones serán dos fundamentales: los documentos donde están escritos los signos u oddun de Ifá (donados por un creyente ${ }^{8}$ ) y la experiencia directa en campo del autor, quien durante cinco años estuvo investigando estos temas con colaboradores de la Casa Esquerra, una de las casas de Ifá más antiguas de Cuba, ubicada en San Juan de los Remedios, en la provincia de Villa Clara. ${ }^{9}$ El método utilizado en este trabajo de campo fue básicamente el etnográfico, privilegiando las

[7] Según Rómulo Lachatañeré: "Cuando la deidad concede dádivas viene el mimo, el uso de diminutivos y cierta correspondencia filial, hasta que el acólito -esto depende de su propia educación- desnaturaliza la franqueza en su trato con la deidad, pierde el sentido del límite y usa la arrogancia para tratar al ángel guardián. Pero la deidad parece que espera estas actitudes, estas alternativas en el trato, puesto que en tales situaciones cruza insultos con el acólito, y nadie es más cínico que el santo para recibir y responder, con certeza y agudez(sic), las frases en tono subido de sus seguidores." Lachatañeré, Rómulo. Manual de Santería, La Habana, Editorial de Ciencias Sociales, 2014, p. 37

[8] Este creyente no está relacionado de ninguna manera con la Casa Esquerra y reside en la provincia de Sancti Spíritus, municipio de Cabaiguán. Su nombre y cargos religiosos se mantienen en secreto por razones éticas. Más adelante se explica en qué consiste el sistema adivinatorio de Ifá.

[9] Esta casa fue fundada por Jacinto Esquerra (Otura Meyi), quien fuera iniciado en Ifá por Taita Gaitán, uno de los ahijados de Ño Remigio Herrera (Obbara Meyi), más conocido como Adde Shina, muy respetado por ser uno de los primeros en introducir Ifá a Cuba desde África (V. Bolívar, Natalia. Los orishas en Cuba. Editorial José Martí, La Habana, 2017, pp. 30-31) Al menos es lo que se cuenta en la casa. Ese fue el lugar donde estuvo Fernando Ortiz en San Juan de los Remedios, recabando información para su libro "Historia de una pelea cubana contra los demonios". De hecho, en la casa aún se muestra una habitación denominada "el cuarto de Don Fernando Ortiz". Lamentablemente nada de esto se ha registrado en investigaciones anteriores. 
técnicas de observación participante y la aplicación de entrevistas en profundidad. Se participó en las partes públicas de varias ceremonias, algunas adivinatorias, la mayoría de iniciación en alguno de los grados posibles dentro de la santería ${ }^{10}$. Se entrevistó a nueve creyentes, tanto no iniciados, como appetebís, santeros y babalawos. Las conversaciones informales con muchos otros no cuantificados arrojaron elementos de gran importancia para la mejor comprensión de su perspectiva religiosa y su vivencia cotidiana de la misma. También se recurrió al análisis documental de los textos publicados por otros investigadores, como Lydia Cabrera, Natalia Bolívar, Fernando Ortiz y Rómulo Lachatañeré.

Resulta muy importante señalar que una de las mayores dificultades de este trabajo es explicar según normas occidentales una manera de entender al mundo, a lo numinoso y a sí mismo que toma como punto de partida principios totalmente distintos a los que se manejan comúnmente. La superficial cristianización de la santería, e incluso su nombre, resulta engañosa. Bajo una supuesta veneración al santoral católico, los esclavos africanos, primero, y luego sus descendientes lograron mantener con sorprendente pureza su lenguaje, costumbres, moral, religiosidad y una cosmovisión ajena incluso a la periférica occidentalidad del resto de la sociedad cubana. Muchos de estos elementos aún se mantienen en un riguroso secreto ritual o detrás de locuciones en un idioma que se va olvidando, cumpliendo casi el mismo papel que el latín en las misas populares. Por esto, la manera de presentar el trabajo toma como referente la "descripción densa" de Clifford Geertz, ${ }^{11}$ tratando de que la interpretación por parte del autor capte de la manera menos sesgada posible las propias interpretaciones que los creyentes ofrecen sobre sus maneras de entender las cosas, no siempre monolíticas, cohesionadas o estructuradas de manera comprensible para la razón occidental.

Según François Houtart la organización religiosa sería "el conjunto estructurado de actores que ejercen un papel religioso específico, con una base material y organizativa que permite el funcionamiento de los sistemas religiosos." 12 La santería, sería, de acuerdo con la conceptualización de este autor, un sistema religioso fundamentalmente expresivo, es decir enfocado en sus funciones rituales ${ }^{13}$. Sin embargo, debido a sus propias

[10] Se participó en varias consultas de Ifá, algunos ebbó, ñangareo, iyoyé, wemileres, ceremonias a eggún y algunas otras ceremonias de carácter más individual. Las mismas no pueden ser explicadas en detalle por cuestiones de espacio.

[11] V. Geertz, Clifford. La interpretación de las culturas, Barcelona, Editorial Gedisa S.A., 2003

[12] Houtart, François. Sociología de la religión, La Habana, Editorial de Ciencias Sociales, Ruth Casa Editorial, 2006, p. 104

[13] Houtart, François. Op. Cit., p. 113. 
características esenciales, sumadas a su largo proceso de hibridación y segregación social, la santería no tiene una organización única, jerarquizada, ni una expresión arquitectónica: los templos son las casas de los practicantes (por eso se les denomina así: ilé, esto es, casa) o en todo caso, la propia naturaleza, el bosque, la orilla del río o de la mar, etc. Incluso las propias manifestaciones rituales cambian de casa en casa. Tampoco hay una serie de escrituras sagradas: el corpus mitológico y ético se transmite de manera oral, a partir de los patakis ${ }^{14}$, que son cohesionados como parte de los diferentes sistemas adivinatorios de la santería ${ }^{15}$. Por esto, la adivinación juega un papel central en esta religión, no solo es el núcleo del propio sistema religioso, sino que estructura la conducta del creyente, su cosmovisión y sus códigos éticos ${ }^{16}$.

Para explicar de manera más sistemática (hasta donde es posible en estos casos), se parte del que podría ser denominado patakí fundacional del sistema adivinatorio yoruba en general, el que da la explicación de la importancia de la adivinación misma. Según las creencias de los santeros, antes de nacer, cada orí escoge ante Olofir ${ }^{17}$ su camino, el cual es representado por los oddun de Ifá, en presencia de Orula ${ }^{18}$, quien funge

[14] Historia mítica, muy a menudo en forma de fábula, a partir de la cual se transmite una enseñanza o una explicación a los creyentes. (V. Natalia Bolívar, Op. Cit., p. 346)

[15] Esta serie de patakíes están en su mayoría dentro del cuerpo adivinatorio del cual se hablará en breve con más profundidad y fueron trasmitidos oralmente durante siglos, luego recogidos en las libretas de santo y hace muy poco recopilados por investigadores que las han sacado a la luz de manera muy fragmentaria. De ahí la importancia de la adivinación, no solo como acto predictivo o conformador de la individualidad, sino también, como núcleo aglutinador de las historias que construyen el cuerpo mitológico de la santería. No obstante, de una casa a otra, de un practicante a otro, estas historias pueden variar, así como las prácticas rituales y concepciones sobre la religión misma. Quizás la única parte del corpus de la santería que es más homogéneo en el país es el sistema de adivinación de Ifá, sobre el que se profundizará más adelante.

[16] Al respecto, Rómulo Lachatañeré asevera: "El oráculo desempeña un rol de gran importancia en el sistema de cultos lucumí. Es el instrumento oficial y retribuido por donde la deidad, controlada conscientemente por el sacerdote convertido en adivino, establece un nexo estrecho no con el cliente, pero sí con las relaciones de este con el ambiente. El oráculo acumula toda una serie de situaciones -por muy transcendentales o mínimas que estas sean- que moldean las posturas del individuo frente al medio donde unas veces ha de luchar con armas legítimas; otras, presionado hacia la periferia de la sociedad donde ha de actuar de acuerdo con su propia ley, en antítesis de una sociedad que le brinda muy pocas posibilidades para mantener una actitud enhiesta." Lachatañeré; Rómulo. Op. Cit., p. 48

[17] Olofi es la deidad suprema, en realidad, es el verdadero dios, en tanto los orishas son sus intermediarios. Algunos autores afirman que conforma una trinidad con Oloddumare (vendría siendo el todo, el universo mismo) y Olorun (el sol, la manifestación material de dios mismo). Pero en realidad es una suerte de deus otiotus, las verdaderas fuerzas actuantes son los orishas, por lo cual a Olofi solo se le menciona o canta, pero rara vez se le rinde culto, excepto en tanto Olorun. Natalia Bolívar afirma que esta idea de una trinidad yoruba es una explicación occidentalizante, forzada, de estas divinidades, de las cuales, en realidad, no se conoce mucho. V. Bolívar, Natalia. Op. Cit., pp. 105- 109

[18] Es el orisha de la adivinación, el que conoce el destino de cada cual y por ende a quien se le puede pedir consejo veraz. Se supone que lo sabe todo y lo soluciona todo. V. Bolívar Natalia. Op. Cit., pp. 283- 287 
como testigo. Cada orí es además puesto bajo la protección un Ángel de la Guarda ${ }^{19}$, quien lo acompañará a lo largo de la existencia terrenal de cada individuo ${ }^{20}$. Hay varias ideas aquí para explicar. En primer lugar, orí es la divinidad individual que cada persona tiene localizada en la cabeza ${ }^{21} \mathrm{y}$ a veces se españoliza como la cabeza en general ${ }^{22}$. Este mito permite explicar las diferencias de las dos ramas de la santería: la Regla de Osha y la Regla de Ifá. De manera muy rápida se puede esbozar que la Regla de Osha se dedica a la veneración del orisha personal o Ángel de la Guarda y de llevar al creyente hasta donde el orisha indique dentro de la religión, es decir desde ponerse collares hasta hacerse santo; mientras la Regla de Ifá se encarga de determinar cuál es el camino que la persona tiene, es decir, escogió antes de nacer, y cómo puede vivir de la mejor manera de acuerdo con este.

La Regla de Osha sería entonces la serie de prácticas que conlleva la adoración al orisha de cada uno, el Ángel de la Guarda. Si la adivinación ${ }^{23}$ así lo requiere y el orisha (o santo, como también se le dice) lo pide, la persona debe iniciarse, hacerse santo o coronar su cabeza. Es decir, pasará por un proceso iniciático en el cual se cree que los poderes del santo se depositan de alguna manera en la cabeza de la persona, o más propiamente, en su orí. Sin embargo, no es imprescindible este proceso para practicar la religión, de hecho, la iniciación suele ser precedida por un proceso gradual de entrega de diferentes elementos religiosos. En la Regla de Osha cualquiera puede ser iniciado, sin limitación de ningún tipo, solo tiene que ser solicitado por el orisha en algún acto de adivinación.

La Regla de Ifá es una élite, conformada de manera exclusiva por sacerdotes de Ifá, es decir, los sacerdotes de Orula, quienes se consideran como los adivinos por excelencia y que su misión es "salvar al mundo". Solo las personas que hayan sido designadas por Orula mismo pueden acceder a esta categoría, se suele decir que tienen camino de Ifá. Pero aun teniendo

[19] El Ángel de la Guarda es una nomenclatura que se tomó del catolicismo, en realidad es un orisha, al cual se le dice padre o madre. El creyente es hijo de su Ángel de la Guarda. Más adelante se explica las implicaciones de esto.

[20] Es imposible dejar de notar la semejanza con el último mito de La República platónica y con algunos de los mitos del Fedro.

[21] De aquí la prohibición ritual de los creyentes en la santería de que alguien (excepto la madre o el padrino o madrina) les toque la cabeza.

[22] Se podría equiparar a la noción de alma, pero sería una tibia aproximación porque es una deidad, aunque sea individual y como tal, es adorada. Según Natalia Bolívar: "Representa la encarnación del espíritu que reside en la cabeza de cada individuo; es el yo propio, símbolo de predestinación. Es deidad exclusiva de cada persona..." V. Bolívar, Natalia. Op. Cit., pp. 158.

[23] El diloggún, o los caracoles, como se les denomina popularmente, es el método adivinatorio por antonomasia de la Regla de Ocha. 
este camino, según la adivinación, tienen que ser hombres heterosexuales sin ninguna discapacidad física. Ni mujeres ${ }^{24}$, ni homosexuales ${ }^{25}$, ni discapacitados, ni sacerdotes de otras religiones pueden llegar a ser babalawo, que es como se les denomina a estos adivinos. Ellos son los que pueden preguntarle a Orula cuál es el destino de cada persona y cómo se puede ayudar a que cumpla con el destino que escogió desde antes de su nacimiento, de la manera más constructiva posible. Estas personas por regla general suelen hacerse el santo primero y después reciben a Orula en un proceso iniciático mucho más complejo (existen excepciones, pero son muy poco frecuentes). Las restricciones que tienen son mucho mayores que la de los santeros.

Ambas reglas guardan una interdependencia mutua: los santeros deben acudir a los babalawos para ciertas ceremonias y para resolver sus problemas más difíciles, pero los babalawos deben acudir a los santeros para otras ceremonias que no pueden hacer y para iniciarse o iniciar a sus ahijados en Osha. La Regla de Ifá vino a Cuba desde África a mediados del siglo XIX ${ }^{26}$, por lo que es relativamente reciente y muchos santeros dicen que no son necesarios los babalawos y prescinden de ellos. No en toda Cuba la presencia de Ifá es proporcional: en el poblado de San Juan de los Remedios son los babalawos los que determinan a partir de la adivinación el Ángel de la Guarda de cada persona, pero en otros poblados muy próximos, en la misma provincia, lo hacen los santeros. Así que la relación entre las reglas es conflictiva y sumamente específica en cada zona ${ }^{27}$. A partir de aquí, se tratará de explicar el proceso de individualización al que es sometido cada creyente ${ }^{28}$ por parte de cada rama.

[24] El escalón más alto al que pueden aspirar las mujeres dentro de Ifá, es a appetebí, un cargo ritual al que a veces se le llama "secretaria": consiste en apoyar a los babalawos en ciertos rituales, en preparar ciertas comidas, en servir la mesa en ciertas ocasiones y ayudar a su padrino en todo lo que necesite.

[25] Sin embargo, existen referencias por parte de los creyentes de que es posible que un homosexual se haga babalawo, siempre que renuncie a su vida sexual y Orula haya dictaminado que es imprescindible hacerlo: hay patakíes que referencian esto. Así, en Oggunda Keté, uno de los oddun, se habla de la ceremonia que se tiene que llevar a cabo en estos casos, denominada sellamiento del oriolo (ano). Los detalles de este ritual son secretos. También existe un patakí que justificaría que las mujeres consulten con Ifá, pero la respuesta de los creyentes es que no pueden hacerlo por dos razones: porque no pueden guardar los secretos y porque menstrúan. De hecho, las mujeres deben quitarse los collares cuando estén en el período de la menstruación y tampoco deberían acercarse a los santos en ese tiempo, incluso hay ritos de recepción de santos que solo pueden hacer luego de la menopausia.

[26] V. Aboy Domingo, Nelson. Orígenes de la santería cubana. Transculturación e identidad cultural. Editorial de Ciencias Sociales, La Habana, 2016, pp. 89- 92

[27] También hay una nueva corriente en la santería que plantea regresar a las fuentes originales africanas, denominada Ilé Tuntun que inicia a mujeres en Ifá, entre otras adaptaciones rituales.

[28] La propia noción de creyente ya es complicada, porque debido a la atención individualizada para cada uno podría preguntarse: ¿quién puede ser considerado creyente? ¿Aquel que así lo refiera, quien tenga 


\section{Identidad y Regla de Osha. El Ángel de la Guarda, "hacerse el santo" y los caracoles}

Como ya se ha dicho, el Ángel de la Guarda es el nombre catolizado del orisha de cabecera, es decir, aquel orisha que es el padre o la madre del creyente, el que lo acompaña, lo alecciona, lo castiga, en sus pasos por la tierra. Cada orisha es la personalización de una fuerza natural o social y tiene una serie de patakíes que describen las relaciones entre ellos, sus disputas, sus amoríos, sus temperamentos, aquello que comen y lo que no, las ropas que usan, los colores que prefieren ${ }^{29}$. Esto implica que, una vez que la persona por adivinación conozca su orisha, tendrá todo un complejo sistema de historias a partir de las cuales comprender su propio comportamiento y el resto de los creyentes aprobarán, justificarán o condenarán su conducta de acuerdo con esto. Fungirá como el principio de la legibilidad cultural del creyente, el cual será entendido como hijo/a de...y a partir de allí se espera de él/ella una cierta manera de ser. Por ejemplo, un hijo de Shangó, el orisha del rayo, una clara representación falocéntrica y patriarcal, será, o se espera que sea, arrogante, pendenciero, machista, infiel, inteligente, fiestero, mentiroso, hipersexual e incluso se supone que tenga un gran pene. Una hija de Oshún, la orisha del río y del amor, será alegre, dulce, sufrida, rencorosa, manipuladora y, en muchos casos, si es promiscua será comprendida y justificada, porque Oshún según las historias en algún momento fue panchagara (literalmente, puta) ${ }^{30}$. Un omó (hijo/a) de Yegguá, una de las orishas del cementerio, quien representa el proceso de putrefacción de los cadáveres, está obligado/a una vida de castidad absoluta, pues su madre fue violada de niña y desde entonces aborrece todas las prácticas sexuales ${ }^{31}$.

Además, cada creyente tendrá restricciones alimentarias y de otras índoles, de acuerdo con su Ángel de la Guarda; sobre todo será así luego de la iniciación, cuando tenga el santo hecho. Antes, las recomendaciones son menores en cantidad y en obligatoriedad. De manera general los tabús

collares o haya recibido algún objeto ritual, quien se haya iniciado? Muchas personas en Cuba, a pesar de ser practicantes de otras religiones acuden a los santeros cuando necesitan resolver algo. Además, en la santería, a diferencia de las iglesias cristianas no existe un momento ritual determinado y general (el mismo para todos) a partir del cual se pueda considerar al creyente como miembro de la comunidad religiosa.

[29] V. Cabrera, Lydia. El monte, La Habana, Ediciones Letras Cubanas, 1993 y también: Natalia Bolívar. Op. Cit.

[30] Según esta lógica, un hijo de Oshún que sea adodi (homosexual) no sería motivo de sorpresa, debido a la intrínseca feminidad de su madre.

[31] No es de extrañar que sea una de las orishas menos populares, excepto en la región oriental, sobre todo en Santiago de Cuba, donde es muy reverenciada. En el centro del país es casi desconocida y no se ha tenido la oportunidad de verla en ninguno de los altares o "canastilleros" a los que el autor ha podido acceder. 
para el creyente son aquellas cosas que representan a su santo y/o lo que come. Por ejemplo, Shangó come carnero y su olor es el rojo, sus omós debe evitar el carnero, los frijoles colorados, la cebolla morada o cualquier otro alimento de ese color. Obbatalá es el/la dueño/a de las cabezas y su color es el blanco, sus hijos/as no pueden comer cabeza de ningún animal, ni cangrejo (porque no tiene cabeza) ni judías (frijoles blancos), ni huevo, ni coco, tampoco pueden beber bebidas alcohólicas de ningún tipo (porque pierden la cabeza). Oyá es la portera del cementerio, quien recibe a los muertos, por eso sus hijos/as no deben vestir de negro (el color de la ropa de Ikú, la muerte), ni acercarse a enfermos terminales (porque se los llevan).

Esta situación se complejiza con los caminos de cada orisha. Los caminos son como variantes de cada uno de los santos, sus avatares. Los creyentes los describen como momentos de la vida de ellos, cuando estaban aún en la tierra. Por ejemplo, Obbatalá tiene dieciséis caminos, ocho mujeres y ocho hombres, por eso se habla indistintamente de él/ella. Elegguá, el orisha que representa al azar y al destino, tiene ciento uno caminos reconocidos: en algunos es niño, en otros es adolescente, a veces un anciano; puede ser verdaderamente diabólico y asesino, o solo travieso. Oshún tiene caminos donde es reina, en otros es prostituta, en uno es sepulturera, en su peor variante es una mujer muy desafortunada en amores que terminó siendo una bruja malvada, pordiosera, que come la carroña que le traen sus únicas amigas, kolé, las auras tiñosas ${ }^{32}$ (por eso la orisha en este camino se llama Oshún Kolé). Yemayá en casi todos sus caminos es reina, sin embargo, en uno es herrera y no vive en el mar sino en el monte, en otro vive en las letrinas contando compulsivamente las plumas de los gallos que le sacrifican, sorda a las peticiones de sus hijos hasta que termine la cuenta interminable que reinicia cada vez que se confunde ${ }^{33}$. En el caso de otros orishas, como Oyá, prácticamente solo se conocen los nombres de los caminos, sin que sea posible distinguir unos de otros. Así el creyente sería determinado no solo por su orisha, sino también por el camino del mismo que le corresponda $\mathrm{a}^{34}$.

No se abordará aquí en profundidad la complejísima ritualidad de la santería ${ }^{35}$, pero el momento de la iniciación es un clímax en este proceso de identificación con su orisha de cabecera. Sobre todo, en el día del me-

[32] Una especie de buitre muy común en Cuba. Su nombre científico es Cathartes aura.

[33] Hay un camino, Akuara, donde Yemayá y Oshún se confunden. Yemayá representa al mar y Oshún al río. Akuara es entonces la desembocadura y se le dice indistintamente Oshún Akuara o Yemayá Akuara. A sus hijos/as se les dice "hijos/as de las dos aguas" y se supone que tenga rasgos de ambas orishas.

[34] Aunque antes de la iniciación es posible saber quién es el Ángel de la Guarda, solo después de hacerse el santo se puede saber cuál de los caminos es el que le corresponde a cada creyente.

[35] Muchos de sus principales momentos rituales son secretos. 
dio, es decir el día después de que le sea puesto el santo en la cabeza ${ }^{36}$. Lo ritual mismo se convierte en una tecnología performática muy sofisticada de producción de un sujeto o al menos de su individualización. Su cambio de status religioso se interpreta como un nuevo nacimiento dentro de una nueva matriz simbólica que reconfigurará su vida de manera permanente y definitiva ${ }^{37}$.

El día siguiente del "día del medio" se lleva a cabo la ceremonia del itá, donde se consulta con el diloggún (o como se le conoce popularmente, los caracoles ${ }^{38}$ ), el destino de la persona, nuevas regulaciones y demás. Este sistema adivinatorio, exclusivo de los santeros, consiste en dieciséis caracoles cauris que son lanzados al suelo y en dependencia de la cantidad de caracoles que caigan con el agujero natural hacia arriba o hacia abajo se saca una letra o un signo. Son dieciséis posibilidades, por tanto, son dieciséis signos posibles, aunque a veces se tiran dos veces haciendo mayor la cantidad de combinaciones. Este signo será determinante en la vida de la

[36] En el día del medio, la persona debe estar vestida en un trono, con la ropa y los atributos de su orisha y recibirá los saludos de todas las personas de la "casa" en nombre de su santo. Después pasará una semana vestido de manera especial, será bañado y tratado como a un recién nacido. A partir de allí dejará de celebrar su cumpleaños para celebrar como tal el día de su iniciación. Dormirá una semana en una estera junto a los receptáculos donde se les entregan las fuerzas de los orishas que debe atender. Esa semana es generalmente en casa del padrino o madrina y no debe salir de allí. Después comienza el año del yaboraje. Antes de la iniciación la persona debe despojarse de toda su ropa anterior, pues pasará ese año vestido/a de blanco. Durante ese período nadie debe llamarle por su nombre, se le debe decir yabó y los creyentes con los que se cruce en la calle cruzaran sus brazos sobre el pecho para saludar al orisha que representa. Debe ser acompañado a todas partes, no debe tomar sol y evitará las aglomeraciones de personas.

[37] La personalización se manifiesta de manera evidente incluso en que después del ituto (la ceremonia funeraria que se hace a los iniciados difuntos) la mayoría de sus objetos religiosos son rotos y llevados a los lugares "donde los santos digan". Puede ser al río, al mar, al monte, a los pies de una ceiba, etc. En raras ocasiones los santos deciden quedarse con alguna otra persona, pero aun así se supone que esta no puede "trabajarlo" sino solo "atenderlo". En la Casa Esquerra es impresionante la cantidad de Eshus que "pidieron" quedarse en la casa, luego de la muerte de sus dueños.

[38] Existe otro método adivinatorio: el obí (coco) que es mucho más simple e incluso puede ser utilizado por los aleyos, pero por su "simplicidad" (solo en comparación con los otros dos métodos) no será abordado en este escrito. Sin embargo, no es posible soslayar que resulta determinante en la actuación cotidiana de los creyentes, sobre todo de los no iniciados, pues cualquier decisión transcendental de su vida deben consultarla antes con el santo y el único medio directo sin ir a su padrino o madrina es preguntándole al coco. V. Bolívar, Natalia. Opolopo owó. Los sistemas adivinatorios de la Regla de Ocha, La Habana, Editorial de Ciencias Sociales, 1994 
persona $^{39}$. Las letras de los caracoles son equivalentes a los dieciséis oddun mayores de Ifá ${ }^{40}$.

Finalmente, la apoteosis literal del creyente está en el acto teofánico de la posesión, del trance. Cuando se le monta el santo, o se le sube, el creyente deja de ser él para ser un cuerpo a partir del cual se manifiesta su orisha. Para esto no hace falta tener santo hecho. El orisha libérrimamente escoge entre los presentes (el espacio por excelencia del trance es la fiesta, el bembé o wemilere) a quién montará. Resulta interesante que puede haber más de un creyente poseído por el mismo orisha y aunque puedan hacer cosas diferentes, la gestualidad y la expresión facial suele ser muy semejante. Para esto no existen barreras de género: si el Ángel de la Guarda es femenino y posee a un hombre este se manifestará como mujer y viceversa. Sin embargo, este trance no lo consideran una cuestión eucarística: la mayoría, en cuanto los tambores tocan a su santo, o se apartan o bailan más despacio ${ }^{41}$ o toman una serie de medidas para no entrar en trance. La explicación de los creyentes fue que tal estado representaba demasiado esfuerzo físico y que se sentía mucho agotamiento después, al recuperar la conciencia. Pero, ser un buen caballo de santo y que el santo lo monte bonito (o le dé bonito) hace ganar el respeto en la casa ${ }^{42}$, por lo que

[39] En esta ceremonia también se le asigna a la persona el otro orisha de quien es hijo/a. Es decir, si el Ángel de la Guarda es masculino, este es el padre y se le investiga (por adivinación) quién es su madre o viceversa. Los affaires que hayan tenido los orishas según los patakíes no son determinantes en este sentido. Eso implica que hay otro orisha que determinará la identidad de cada sujeto, aunque siempre en menor medida: no sería igual un hijo de Oshún y Shangó, que un hijo de Oshún y Obatalá, etc. Es importante también señalar que cada uno de los signos puede salir en iré u osobbo. Iré es la polaridad positiva, a veces se le dice el "bien", pero es inexacto, porque no tiene connotaciones morales. Osobbo es lo contrario, la polaridad negativa. Existen más de diez formas de iré y de osobbo, lo cual multiplica la singularidad posible de cada signo exponencialmente.

[40] En Osha, además, se realiza un ritual, denominado pinaldo, donde se "da el cuchillo", es decir la autorización ritual de matar animales de cuatro patas, en la cual se hace otro itá menor. También ocurre con la entrega de Olokun, una deidad marina, quien, al menos en San Juan de los Remedios, en el acto de entrega, hecho por los santeros, se leen los caracoles y se le "quita" o recomienda al creyente lo que diga el signo. Sin embargo, este es un caso atípico porque en otras regiones del país lo entregan solo los babalawos, pero sobre esa modalidad, más general, no se tiene referencia etnográfica. Es decir: las personas suelen pasar por muchos rituales en los cuales se le hacen nuevas prohibiciones. En el caso de los babalawos por ejemplo, tendrían como mínimo tres itá: el del awofaka, el de Osha y el de la ceremonia de hacerse babalawo.

[41] Esto del baile es un aspecto muy complejo dentro de la ritualidad de la santería. Cada santo (al menos los mayores) tiene una complicada coreografía que se baila cuando los tambores tocan sus oro seco (solo percusión) o se cantan sus cantos además del toque. Para esto se sigue cierto orden dentro de la liturgia. Pero además cada canto habla de diferentes caminos del orisha y los movimientos cambian. De alguna manera, el creyente debe aprender a bailar los pasos básicos de su orisha y a partir de allí puede hacer variaciones. También esto colabora con la identificación del creyente con su orisha y logra reproducirlo a un nivel gestual incluso; por eso algunos santeros pueden decir que alguien "tiene cara" de ser hijo de Yemayá, tiene la risa de Oshún o la mirada de Oyá.

[42] No obstante, todos los orishas no se suben y algunos lo hacen en contadísimas ocasiones. Orula, por 
hay un conflicto de aproximación- evitación, muchas veces, así como actos de franca impostura, reconocidos por determinados trucos de los creyentes, sobre todo cuando le ocurre a alguien no conocido o nuevo.

Así, atribuirle a alguien un Ángel de la Guarda es un acto individualizante, que progresivamente irá recreando la identidad del creyente en todas las áreas de su vida, reforzado por lo que esperan de él los demás practicantes, por el sistema adivinatorio del diloggún, por la ritualidad, por el trance y, sobre todo, por el proceso, siempre progresivo, de la iniciación.

\section{La Regla de Ifá y el signo personal}

El sistema adivinatorio de Ifá está basado en el ékuele, una cadeneta con ocho pedazos de coco o de caparazón de jicotea que se lanza sobre un tablero. En dependencia de si caen cóncavas o convexas las piezas, se leen los oddun, signos o letras. Hay dieciséis oddun mayores, llamados meyis, equivalentes a los signos del diloggún. Estos meyis se combinan entre sí, dando como resultado doscientas cincuenta y seis combinaciones posibles. Cada signo representa el surgimiento de elementos naturales y sociales, partes anatómicas, emociones, etc.; se relacionan con planetas, orishas y días de la semana, con plantas (ewe), se les hacen prohibiciones y recomendaciones. Se le atribuyen debilidades orgánicas o emocionales. Estos signos son frutos de un saber ancestral que parte de cierto orden cosmovisivo de origen africano, pero que se ha ido recreando en suelo cubano con un increíble carácter plástico: Ifá ha asumido objetos, ideas e historias que son originarias de otras culturas y las ha incluido en su concepción del mundo ${ }^{43}$, como en un palimpsesto donde se ha ido reescribiendo la historia de la cultura cubana y sus influencias. Cada oddun además tiene una serie de refranes asociados y varios patakís (a veces fábulas occidentales han sido tomadas como parte de este corpus), que actúan como el marco simbólico de las reglas a seguir en la vida de cada persona. Las características personológicas asociadas al signo, no siempre son las deseadas ni esperadas por la moralidad occidental de inspiración cristiana ${ }^{44}$.

ejemplo, no se sube y si a alguien se le sube el santo queda automáticamente descartado para Ifá, porque los babalawos no deben ser caballos de orisha ni de eggun.

[43] Un caso notorio es como en el signo Osa Loni nace "la explotación del hombre por el hombre", tomando una idea de uso corriente en Cuba a partir de la introducción del marxismo soviético y usándola para explicar las características personológicas del "hijo" de este signo y las recomendaciones mágicas a acatar.

[44] Cada signo tiene también una serie de obras y ebbó (trabajos de índole mágica) que llevar a cabo como obligación. Como ese es el verdadero secreto del ifaísmo (lo demás puede ser divulgado sin óbice alguno) y además no es necesario para el objetivo de este escrito, no serán descritos. Sobre las obras hay 
A Ifá, como al diloggún, acuden personas en diferentes momentos de su vida, en general por situaciones difíciles. Se lleva a cabo una "consulta" o "vista", en la cual se le pone el ékuele en la cabeza al consultado y se lanza. El signo que salga es leído y se dan las recomendaciones pertinentes así como se recomiendan las "obras" mágicas necesarias que van desde ofrendas muy simples o rezos hasta sacrificio de animales de cuatro patas ${ }^{45}$. En casos extremos, se acude a la iniciación "urgente" de la persona. Cuando es un cliente asiduo, el babalawo va haciendo generalizaciones de los rasgos que más salen en cada consulta ${ }^{46}$ y así construye junto al individuo una serie de recomendaciones, las cuales aún no son obligatorias. Las mismas se vuelven tales cuando Ifá dice que hay que darle al creyente la mano de Orula.

Es esta una serie de ceremonias, que en el caso de los hombres se llama awofaka y sería el paso previo para que se inicie como babalawo, siempre que tenga camino de Ifá y no tenga las limitaciones ya comentadas, si no, es el máximo grado al que puede llegar en Ifá, como ocurre con las mujeres, para las cuales el proceso se llama ikofá y las hace appatebí (a veces se les dice, las mujeres de Orula o las secretarias de Orula). Saltando los detalles rituales, muy complicados y de varios días, lo central es que en ella se considera que se descubre el signo de la persona (y en el caso de

un detalle que es importante señalar: cada signo tiene varias obras, pero todas las personas no tienen que hacer las mismas y cada una puede tener variantes que se descubren por adivinación. Respecto a esto es muy determinante si el signo está en iré y en osobbo o el orisha con el que hay que trabajar. También depende de las propias prohibiciones que tenga el padrino a la hora de matar ciertos animales o realizar ciertas prácticas. Cada una de estas "obras" o ebbó, sobre todo a partir de recibir "la mano de Orula" tiene un carácter performático, no es solo para cumplir el objetivo pragmático de resolver algún problema cotidiano por una vía mágica, sino también para "reforzar" el orí de la persona, es decir, su principio de máxima individuación. Esta distinción entre objetivos vitales y fortalecimiento mágico sería válida solo para nuestros ojos occidentales; para el santero no hay diferencia: solo puedes tener éxito y salud en tanto estés en concordancia con el destino que tú mismo asumiste antes de tu nacimiento. Se podría utilizar la frase de Píndaro, asumida por Nietzsche y aseverar que el objetivo de la santería es que cada uno/a llegue a ser lo que es, teniendo la menor cantidad de conflictos posibles con la sociedad. Ahora, lo que se es, no se descubre a partir de un profundo acto de introspección, ni en la acción cotidiana, sino a través de la adivinación. Desde ahí se caracteriza a la persona y se le ubica dentro del sistema de relaciones (altamente jerarquizado) de la casa de santo e incluso dentro de la sociedad en general. En este caso es importante destacar que hay varios signos que marcan una profesión determinada, en el caso de los/as niños/as que reciban la mano de Orula desde pequeño/a, en muchas ocasiones se les inclinará a la ocupación que según su signo les toca, así de un Edibre se espera que sea músico/a. Pero incluso en la adultez esto puede ser muy influyente en el redireccionamiento vocacional del individuo.

[45] Esta letra no solo habla para el creyente, sino también para el consultante, sobre obras que debe hacer y sobre el comportamiento que debe tener respecto al consultante.

[46] Esta consulta no se limita a que el babalawo reproduzca lo que sepa de cada letra que salga, al contrario, él tiene un amplio margen hermenéutico. La adivinación es concebida como creativa, es decir, en función del oddun que hable el babalawo toma en cuenta otros factores, como las preocupaciones del consultado, e interpreta lo que quiere decir en ese caso específico. Esto hace cada registro aún más particular. 
que no lo sepa de antemano, su Ángel de la Guarda también), esto es, el destino que su orí escogió ante Olofi con Orula como testigo, representado en uno de los doscientos cincuenta y seis oddun de Ifá. A partir de aquí la persona se considera hijo/a del signo dado y todas las recomendaciones, prohibiciones, refranes y patakís del mismo serán suyos. Como en el caso del diloggún, cada oddun viene en algún tipo de iré u osobbo, lo que hace que, en cada caso, aunque se comparta la letra, sus normas serán distintas, sin contar con todas las demás que dependen de su Ángel de la Guarda y de su signo en Osha. La persona, además, asumirá el nombre de su signo como su nombre ritual y muchas veces será un secreto celosamente guardado porque se considera que quien lo sepa tendrá poder de vida o muerte sobre él/ella ${ }^{47}$.

A continuación, se propone una clasificación de las regulaciones para ofrecer una explicación más detallada de las mismas, a partir algunos ejemplos, que no agotan su amplia variedad. No todos los signos tienen las mismas prohibiciones y la cantidad, tipo e intensidad varía de uno a otro $^{48}$. También se explicarán algunos de los detalles del comportamiento que se cree propio de algunos signos. Para realizar esta clasificación se partió de la revisión exhaustiva de cada uno de los doscientos cincuenta y seis oddun de Ifá, donados en documentos digitalizados por un creyente en el año 2009. Por razones éticas de la investigación no se divulgarán los denominados secretos de los signos. Por supuesto en ningún caso se habla de todos, ni de todas las normas que debe cumplir cada uno. Las frases entrecomilladas son extractos textuales de lo escrito en el oddun.

\section{Regulaciones alimentarias}

Las regulaciones alimentarias son las más conocidas entre la población cubana, los creyentes suelen preguntar con cuidado los ingredientes de cada alimento para evitar que entre ellos haya algo que le sea ewe (comida tabuada, aunque también significa yerba). En el caso de que lo ingieran accidentalmente deben tomar un preparado cuyos componentes más importantes son las hierbas, denominado omiero, para limpiarse el estómago. Los alimentos tabuados son muchos y muy distintos, los más

[47] Esto también implica una relación de poder entre babalawo- ahijado. No en vano en casi cada signo de Ifá se refieren las espantosas consecuencias que tiene la desobediencia a la palabra de Orula (representada siempre por el babalawo) y el enlace ritual-filial establecido se planifica expresamente en función de la dependencia en algunos signos, aunque en otros se prevé la pronta extinción del vínculo.

[48] Algunas de estas normas tienen un porqué mítico, basado en los patakís, otras no se sabe su causa. Por razones de espacio, esas explicaciones se obvian y se limita a la descripción simple de la normativa. Además, su propio carácter no racional las hace particularmente difícil de ser sometidas a explicación. 
generales son la calabaza, el maíz, el cerdo, las bebidas alcohólicas, los mariscos, los frijoles o ciertos tipos, partes y/o preparaciones de estos. Pero ninguno es general para todos los creyentes. Algunos oddun tienen muchas restricciones alimentarias, otros casi ninguna. A estas prohibiciones los creyentes suelen referirse como me quitaron el huevo (o la bebida, etc.).

Muchos no pueden beber bebidas alcohólicas (ninguna), como Ogbe Fun, Irete Laso, etcétera. Ika Ogunda no puede echarles las sobras de su comida a gatos o perros y no puede probar frutas. Irete Ansa puede comer frutas, siempre y cuando las compre, no puede comer las que le regalen y debe evadir comidas calientes, saladas o picantes. Iroso Meyi no come marañón, ni plátanos indios o manzanos, ni ciruelas rojas (porque el color rojo le es tabú en general, tanto en alimentos como en vestuario). Osalofogbeyó no come huevos, ni calabaza, ni acelga, ni chocolate, ni frijoles blancos. Osarete no come con cubiertos de metal: tienen que ser de madera, ni come carne. Otrupon Di no come nada enlatado ni en conserva. Otrupon Niao no puede poner un plato de más en la mesa y no puede levantarse de la misma hasta que termine de comer.

\section{Regulaciones higiénicas}

Hay otro grupo de normas que se considerarían dentro de la higiene, aunque en muchos casos no cumplen con los criterios de la asepsia tan caros a Occidente. Se podría hablar de medidas sobre salud en general, pues cada oddun se considera propenso a una serie de enfermedades e incluso se le indica una o varias causas posibles de muerte ${ }^{49}$, pero eso haría demasiado larga la exposición. Por eso se prefirió solo comentar algunos casos relacionados con los baños y cuidados personales específicos.

Ika Bara debe lavarse la cara con pétalos de rosas y omí tuto (agua fresca) para despojarse de la nostalgia. Irete Yero debe cortarse el cabello cada diez días, pero tiene que tener mucho cuidado con quien le toca el pelo y la cabeza en general; mientras Oddíroso no puede cortárselo. Ni Irete Ansa, ni Irete Unfa, ni Edibre deben mojarse con agua de lluvia. Iwori Batuto debe evitar demasiado sol; Oddí Ogundá debe evitar la luz de la luna. Oggunda Folokana no puede teñirse el cabello y Oggunda Fun se lava la cabeza con otí (aguardiente). Oggundaroso debe lavarse los ojos con orine

[49] Las posibles causas de la muerte también serían muy interesantes para valorarlas, en tanto orientadoras hacia una conducta abocada a eludirlas y siendo entonces individualizantes por evitación. De manera general, casi todas las normas de la santería usan el miedo a la muerte como un incentivo para cumplir con las prohibiciones y recomendaciones. Ikú, de hecho, es un orisha poco querido y para nada adorado (no tiene hijos/as), a diferencia de lo que ocurre en México con la figura de la muerte en general y de la Santa Muerte en particular. 
de niño pequeño. Ojuani Shidí no puede usar perfume. Un caso particular es Oyekun Biká quien no debe entrar en contacto con el agua, sobre todo no puede mojarse la cabeza con ningún tipo de agua (esto incluye aguardiente y agua de colonia) y para bañarse se la debe cubrir con una jicara.

\section{Regulaciones relacionales}

Otras regulaciones van hacia el aspecto relacional de la vida de los creyentes, son más sociales, si se permite el término. Muchas de ellas indican con quién se puede o no relacionar el creyente, de acuerdo a su orisha y al del otro. También determinan quiénes serían los enemigos potenciales (arayes) e incluso regularían los vínculos según normas de género y raza. Incluso determinan la proxémica que pueden tener con otros individuos ${ }^{50}$. Ogbe Fun no debe tener relaciones con "personas coloradas". Ika Bemi debe cuidarse de personas "rubiancas y de mulatos jabados" porque son su araye (enemigo) e incluso no debe tener ahijados. Los arayes de Ika Ogunda son personas delgadas con patillas (barba), pero debe estar cerca de personas negras. Ika Yekun no puede comer en casas ajenas e Irete Laso no puede ir a donde no lo inviten. Irete Oba no se puede dejar abrazar ni que le toquen la cara porque "le pueden llevar la vista" ${ }^{51}$, tampoco puede dejar que alguien extraño le limpie la casa. Okana Bara debe cuidarse de personas blancas sin creencias religiosas ${ }^{52}$. Irete Kutan debe cuidarse de personas tuertas o con defectos visibles en la vista. Ofun Yemiló debe cuidarse de los cojos. Iroso Juani no debe dar la mano al saludar. Obara Dila no debe quitarse el sombrero para saludar a nadie. Ojuani Bokó no puede botar a nadie de su casa y Ojuani Yekún no puede negarle la comida a ninguna persona que se la pida. Ofun Bara "no puede entregarle el corazón a nadie". Ofun Biroso tiene que confesar sus penas para que no lo ahoguen. Oyekun Dí no puede ir a ver a personas en la cárcel, así como Oyekun Pakioshé no debe visitar enfermos.

\section{Regulaciones espaciales y de movilidad}

[50] Esto también se denota en las prohibiciones de sus respectivos Ángeles de la Guarda: por ejemplo, los/ as hijos/as de Oyá no deben tocar la cabeza de los/as de Yemayá y viceversa. En general deben evitar tener relaciones cercanas.

[51] En este caso tener vista es visto como una gracia, un ashé, es decir, la capacidad de ver apariciones y la denominada visión premonitoria.

[52] Es interesante resaltar cómo los arayes siempre son personas de piel más clara, son blancos, colorados o jabaos (mulatos rubios o de pelo claro). En ningún caso se le previene a algún signo en contra de las personas negras. 
Dentro de este ítem se mencionan algunas de las normas de dónde pueden vivir o no las personas, qué lugares deberían evitar y si deben o no moverse de donde están y con cuáles limitaciones, en el caso de que puedan hacerlo. Ogbe Ka no puede dormir en una casa que no sea la suya y tiene que "ir a vivir a otra tierra". Ni Irete Untegdí ni Oddí Kana deben vivir en altos; Iwori Birete debe evitar las alturas a toda costa. Obara Yekun no puede subir escaleras. Irete Wanwan seguramente tendrá muchos viajes, pero debe vivir en una casa con patio sembrado por muchos árboles y no puede pasar el mar ni el río. Iroso Meyi no puede ir al cementerio, Osa She tiene prohibido ir a velorios o entierros. Iroso Umbo no puede entrar en casas vacías. Ojuani Tropun no puede vivir en casas pequeñas. Iroso Wiro tendrá herencia allende del mar, pero puede morir en una travesía marítima $^{53}$. Iwori Meyi no debe entrar en una casa que esté fuera del pueblo ni debe reunirse con tres personas al mismo tiempo. Obara Bogbe debe irse al extranjero, al menos cinco años, porque en su tierra puede sufrir prisión. Oddí She tiene que permutar tres veces de casa. Oggunda Ka es el signo del cementerio de los elefantes, si la persona sale del país se muere allí; al contrario, Oggundaroso viaja pero debe regresar a su lugar de origen aunque sea a morir allí. En Osa Fun "la mariposa no va a la ciudad porque los muchachos la matan", esto es la persona debe vivir en el campo.

\section{Regulaciones sexuales/reproductivas}

Una serie de normas muy interesantes son aquellas relacionadas con las conductas sexuales y reproductivas de los creyentes. Es notable cómo reconocen la existencia de comportamientos no heteronormativos y la posibilidad incluso de que esos creyentes sean iniciados en Osha. Sin embargo tampoco es posible hablar de aceptación incondicional. La conducta heterosexual con fines reproductivos es la preferida: conductas como el sexo oral, el anal y la homosexualidad no son parte de lo considerado preferible o lo normal. Contra el prejuicio que atribuye a lo africano y a lo "primitivo" un comportamiento sexual libérrimo aquí se puede comprobar que está sumamente regulado, a extremos inesperados.

Ogbe Di tiene que ofikale trupon (tener relaciones sexuales) con la obini (mujer) cuando esté menstruando para no quedar impotente. Ika Sa, Irete Sukankola, Iwori Yekun si son obini no pueden abortar. Si Iwori Ye-

[53] El mar, reino de Yemayá, como peligro es muy recurrente en muchísimos otros signos, algunos van desde el mero hecho de estar a la orilla, bañarse, cruzarlo en alguna embarcación hasta bucear, sobre todo, hacerlo con careta es visto como especialmente peligroso en algunos casos, como en Iwori Okana . Sin embargo, a Oddí Sa se le recomienda que se bañe en el mar. A los/as hijos/as de Yemayá se les prohíbe a menudo bañarse en el agua salada. 
kun es mujer, hay un eggun (muerto) que convive con ella y la inclina a ser alakuata (lesbiana) ${ }^{54}$. En Obara Trupon la obini prefiere el endoko (sexo anal) a ofikale trupon y debe evitarlo. Oddí Atakofeño habla de todo tipo de "aberraciones sexuales" (incesto, zoofilia, homosexualidad): se representa por Logbun, hijo de Oshún e Inle, quien era seis meses hombre y seis meses mujer (la persona tendría una explicación ritual para ser trans). Oddírete no puede tener contacto sexual con mujer que tenga sus "partes afeitadas". Oddíroso no puede "brincar mangueras", tiene que pisarlas para no quedar impotente. Okana Wete determina que para el matrimonio no se divorcie deben dormir en la misma cama, pero en diferentes direcciones: uno hacia los pies y el otro hacia la cabecera. Osa She no puede permitir que las mujeres le pongan las manos en la espalda. Osalofogbeyó no puede tener relaciones de ningún tipo con adodis (homosexuales) o alakuatas (lesbianas), sin embargo, sí con panshagaras (prostitutas): "la felicidad de Osalofogbeyó es vivir con una mujer que haya puteado bastante." No obstante, es "camino de pederastia activa y pasiva". En Otura Mun nace que el mamu obo (sexo oral a la mujer) hace perder el ashé. Oyekun Nilogbe en el acto sexual no puede tener a la mujer encima.

\section{Regulaciones religiosas}

Además de la santería, en Cuba existen la Regla del Palo, la sociedad abakuá, el espiritismo cruzado $^{55}$ y el vudú. Es muy frecuente que el mismo creyente practique varias de estas religiones al unísono. También en Ifá se regulan si según su signo debe o no pertenecer a alguna y a cuál debería ser ${ }^{56}$. Ogbe Sa no puede tener "prenda", es decir no puede ser pa-

[54] Es frecuente que se considere que algunos signos sean propensos a que algún eggun "haga vida" (es decir tenga relaciones sexuales) con ellos y si estos eggun son del mismo género de la persona los "hacen" homosexuales. También pueden alejar de la persona a cualquier posible pareja por celos o la llevan a una vida sexual muy promiscua. Para librarse de los eggun "obsesores", sean de esta índole que recuerda a los súcubos e íncubos o de otra, se hace una ceremonia denominada oparaldo, pero incluso estas ceremonias son diferentes en cada caso.

[55] En el caso del espiritismo cruzado o de cordón, si se le sugiere al creyente que lo practique, es otro proceso de individualización: cuando se determina por la "visión" o la posesión del médium (también se le dice caballo, como en el caso de la santería, si hay mucha influencia del palo se le llama "perro de prenda") la "bóveda espiritual", esto es, los muertos o seres espirituales (no siempre humanos) que acompañan al creyente se le explican las características personológicas de cada una de estas entidades. La conducta del creyente se considera que es también determinada por las mismas. Una persona que tenga de muerto principal a una monja será recatada, mientras quien tenga un indio o un negro cimarrón será violento o de carácter fuerte. También puede haber espíritus gitanos, chinos e isleños (canarios). Pero este tema sería demasiado complicado para tratarlo aquí, además, es mucho menos estudiado que las religiones de origen africano.

[56] Hay muchas otras regulaciones religiosas que tienen que ver con qué hacer o no dentro de la propia santería, pero como eso forma parte muchas veces de los secretos de cada signo se prefiere no abordarlo, 
lero. Irete Kana no debería "andar en el espiritismo", en tanto Iwori Bode debe ser espiritista. Irete Yekun tiene que mandar a decir misas por sus familiares y amigos difuntos, debe visitar iglesias abandonadas. Obara Bogbe si es obini no "puede montar santo" porque se lastima. Obara Trupon, Oddí Atakofeño no pueden bautizar a nadie. Oddí Bara nació para ser esclavo, por tanto, se le recomienda que sea esclavo de los orishas, para que no sea esclavizado por los hombres.

\section{Regulaciones morales}

Existe un grupo de normas en algunos casos que, aunque podían ser incluidas dentro de las relacionales se prefirió exponer fuera por su fuerte contraste con la moralidad de raíz occidental que también es la hegemónica en Cuba. A partir de estas regulaciones es posible comprobar el amplio margen de distancia en la conducta normada para un creyente respecto a otro y, por supuesto el abismo que separa esta moralidad de la que es asumida por el resto de los cubanos, sobre todos aquellos de educación cristiana. Ogbe Kana no puede recoger animales enfermos para curarlos ni "recoger en su casa a nadie" y por mucho bien que haga será desacreditado. Osa Woriwó puede perder la vida por hacer favores. Oggunda Biodé no puede compadecerse de nadie y debe dejar que cada cual se las arregle como pueda; a Otrupon Bara se le recomienda: "No le haga mal a nadie, pero tampoco ayude a nadie para que usted no se atrase. No le haga favores a nadie y a enfermos o inválidos, menos."

\section{Regulaciones temporales}

Las regulaciones temporales son las menos frecuentes de todas, pero existen y se quiso dar algunos ejemplos de ellas. La recomendación más general es que se evite estar fuera de algún lugar techado a las 12 en punto sea del día o de la noche, pero fuera de eso, lo demás es muy particular para cada caso. Irete Untelú no puede cortar yerbas después de las seis de la tarde. Iroso Yeku no debe salir de noche a la calle. Iwori Birete no debe estar en la calle luego de las doce de la noche. Oggunda Yekún debe hacer las cosas más importantes de noche. Ofun Lení debe salir a la calle después de la puesta del sol y evitar salir cuando haya mucho viento. Otura Niko debe trabajar los jueves lo menos posible.

además de que complicaría sobremanera la presente exposición. 


\section{Regulaciones familiares}

La familia tal como es concebida en Ifá sería un interesante tema de investigación para los especialistas. Lo cierto es que no se considera como necesariamente un espacio de ayuda o como una serie de relaciones que deban ser mantenidas a toda costa. Ogbe Kana debe cuidarse de la sobreprotección de su mamá y su abuela, incluso si están muertas, pues por eso no tiene relaciones de pareja felices. Irete Ka para ser feliz debe irse lejos de su familia. Iroso Ka tendrá mala relación con sus hermanos. Obara Koso es "hijo de dos madres", también de Oyekun Meyi se dice que es "hija de dos mujeres". Obara Kuña es propenso al incesto con su hermana. Oddí She tiene que vivir solo. Oggunda Masá debe vivir lejos de su mamá, pero evitar por todos los medios que ella sea su enemiga. Okana Wete no puede contar con su familia.

\section{Otras regulaciones}

Finalmente hay una serie de regulaciones que por su carácter son difíciles de agrupar, muchas son relacionadas con animales, vestuario, objetos o con ciertas acciones cotidianas. Ogbe Fun, Irete Unfa, Iroso Gan, Iroso Umbo no pueden vestir de negro. Otura Mun no debe usar nada rosado en su cuerpo ni en su casa, tampoco sus hijas, mientras vivan juntos. Ika Fogguero no puede tener perros en la casa, mientras Irete Unfa debe tener tres. Okana Meyi no tiene gatos. Irete Laso no puede jugar con armas de fuego, cortantes o punzantes. Ofun Meyi no puede soplar velas ni avivar fuegos. Iroso Juani debe evitar la droga, por su propensión al vicio. Edibre no mata ratones, no puede ser el tercero en usar algo ni puede tener mujer que haya tenido dos maridos anteriores. Okana Sode no regala sombreros ni coronas y no se debe cortar las uñas de las manos; en cambio Oyekun Biká no puede tenerlas largas. Si a Ofun Sa un animal le ensucia la ropa no podrá salir a la calle; en tanto Osaroso debe tener palomas y dejar que le ensucien la casa.

\section{Actitudes ilegales o inmorales}

Muchos oddun presentan rasgos de conducta que son ilegales o inmorales en extremo, según la lógica occidental y, sin embargo, son esperados y justificados por parte de los creyentes. Es válido también reconocer que en Ifá la noción sobre el ser humano en general es bastante poco optimista. Ogbe Bara, por ejemplo, será capaz de todo por lograr lo que 
quiera, es ifá de traición. Ogbe Ka, por su parte "es aquel que es falso como el humo, agrio como el limón y vergüenza de su casa." Iwori Bofun siente placer cuando alguien es maltratado, la persona en ese signo se vuelve un monstruo (signo de los dinosaurios); mientras Otura Bara se reconoce expresamente como el camino del sadismo. En Obara Yekun nace el fumar opio y marihuana, Oddí Oro es traficante de drogas. En Oddí Atakofeño nace que los hombres tengan contacto sexual con chivas y gallinas y las mujeres con perros y monos. Oddí Ka es uno de los "signos malditos": supone premeditación, ensañamiento, alevosía, "no tiene pudor ante el crimen". Varios oddun "marcan" propensión al suicidio (como Oddí Kana). Ojuani Alakentu es "descarado y lo seguirá siendo" y "mal hijo, mal hermano, mal amigo y poderoso enemigo". Ciertos signos están directamente relacionados con entidades que o no son orishas o son los peores aspectos de los mismos; es decir estos oddun deben aprender a relacionarse con lo que en occidente se consideraría diabólico ${ }^{57}$.

\section{Conclusiones}

Cada creyente está regulado por una complicada serie de normas individualizadas por la adivinación tanto de la regla de Osha, como la de Ifá, siendo esta última más estructurada, compleja y homogénea. Qué comer y cómo hacerlo, dónde vivir, con quién relacionarse y a quién evitar, cuáles son los cuidados particulares que se deben tener, qué usar y qué no, qué esperar de la familia y cómo comportarse con ella e incluso cómo tener relaciones sexuales: todo esto está recogido en un conjunto de normas que son determinantes en la vida del practicante, reforzadas además por la promesa del castigo metafísico, pero concreto, de los númenes si no las cumple y por una larga serie de rituales performáticos que van construyendo una identidad pletórica de símbolos.

Pero no es solo qué no hacer, sino también qué hacer. De esta manera se puede entender que el proceso de individualización del creyente no solo restringe la conducta, sino también le abre una serie de posibilidades de ser: algunas en el código occidental serían inmorales e incluso ilegales. Es decir, conforma la identidad de un sujeto en un marco ético que no se corresponde con el hegemónico de la sociedad cubana en general, poniéndolo en una suerte de estado liminal, el cual, curiosamente, rara vez el creyente hace consciente y por ende no se conflictúa. Desde allí desarrolla una identidad anfibia o al menos fluida, que le permite conservar su identidad

[57] Así, Osalofogbeyó debe atender a Abita, quien para los santeros es el diablo mismo. En Otura Yekún por ejemplo, nace el "gran poder diabólico de Eshu" y la "espiritualidad del diablo". 
religiosa sin ser disfuncional en la sociedad en general. Resulta imposible entonces el estudio de la identidad cubana si no se tiene en cuenta esta cualidad rizomática, propia de la santería y de otras religiosidades que se entrecruzan a un nivel cuasi subterráneo en la sociedad, alcanzando incluso a aquellos que no son creyentes.

También es notable cómo estos saberes no occidentales, pero ya mestizos, sea por profecía autocumplida o por efecto del poder de la normativa a la cual se le atribuye un carácter incontestable, se pueden crear conductas, deseos o emociones que quizás en otro contexto no tendrían terreno propicio para su desarrollo. Por ejemplo, el anhelo de migrar, de separarse de la familia, la no solidaridad o ciertas vocaciones. El desarrollo de la individualidad del creyente no pasa solo por lo prohibitivo, sino también por un aspecto propositivo que está deslindado de nociones éticas, al menos de las occidentales. El papel de esta religiosidad en la conformación de la identidad cubana y cómo la misma lo acompaña en los procesos de desplazamiento que implica la migración es un asunto apasionante y casi virgen en el ámbito académico cubano. De esta exposición quedaría una pregunta fundamental: ¿cómo maneja el creyente esta serie de normas una vez que sale de su lugar de origen y entra en otro ámbito social donde las mismas serían, al menos, incomprensibles y en muchos casos no aceptadas? Sobre todo, teniendo en cuenta que para el practicante estas reglas no son exteriores a sí mismo, sino que son constitutivas de su individualidad, son identitarias. Hacia aquí se esbozan los futuros acercamientos al tema. 


\section{Bibliografía}

Aboy Domingo, Nelson. Orígenes de la santería cubana. Transculturación e identidad cultural, La Habana, Editorial de Ciencias Sociales, 2016

Bolívar, Natalia. Opolopo owó. Los sistemas adivinatorios de la Regla de Ocha, La Habana, Editorial de Ciencias Sociales, 1994

2017

Código Penal de la República de Cuba. Disponible en: http://www.parlamentocubano.cu/index.php/documento/codigo-penal/

Cabrera, Lydia. El monte, La Habana, Ediciones Letras Cubanas, 1993

Deleuze, Gilles y Felix Guattari. Mil mesetas. Capitalismo y esquizofrenia. Valencia, Ediciones Pre- textos, 2004

Foucault, Michel. "El sujeto y el poder". Revista Mexicana de Sociología, Vol. 50, No. 3, (Jul.- Sept 1988), pp. 3-20, http://terceridad.net/wordpress/wp-content/uploads/2011/10/Foucault-M.-El-sujeto-y-el-poder.pdf [acceso: 15.05.2018]

Geertz, Clifford. La interpretación de las culturas, Barcelona, Editorial Gedisa S.A., 2003

Harris, Marvin. El desarrollo de la teoría antropológica. Una historia de las teorías de la cultura. Madrid, Siglo XXI de España Editores, 1993

Houtart, François. Sociología de la religión, La Habana, Editorial de Ciencias Sociales, Ruth Casa Editorial, 2006

Lachatañeré, Rómulo. El sistema religioso de los afrocubanos. La Habana, Editorial de Ciencias Sociales, 2001

Manual de Santería. La Habana, Editorial del Ciencias Sociales, 2014

Menéndez, Lázara. Rodar el coco. Proceso de cambio en la santería. La Habana, Fundación Fernando Ortiz, 2002 
$-55-$ 